\title{
SOCIAL AND ECONOMIC ASPECTS OF THE USES OF CAMEL WOOL BY CAMEL HERDERS FOR SUSTAINABLE LIVELIHOOD SPECIAL REFERENCE: SADRI (RAJASTHAN)
}

\author{
DIKSHA GUPTA ${ }^{1} \&$ DR. SHARMILA GURJAR ${ }^{2}$ \\ ${ }^{1}$ Research Scholar, Department of Design, Banasthali Vidyapith, Banasthali, Rajasthan, India \\ ${ }^{2}$ Associate Professor, Department of Design, Banasthali Vidyapith, Banasthali, Rajasthan, India
}

\begin{abstract}
The present study is undertaken to find out the social and economic aspects of the uses of camel wool by camel herders for sustainable livelihood. The study is based on primary and secondary data collection through observation and personal interview schedule. Interviews are conducted at LPPS for camel wool items for the survival of Sadri's camel breeders. It is concluded that camel hair was used to process by the breeders only to make the basic products for their livelihoods. Presently, their social and economic status is very low. Despite all the excellent qualities, Camel hair is most commonly used for basic products like rugs, blankets, ropes, charpais, etc. In products, new designs and existing designs are very simple. There is also a lack of added value products. Breeders and others may endeavor to develop new products that may be of interest to customers in the inner city. And it could contribute to the economic growth of the region and thus prevent migration from maintaining its traditional regional art and crafts.

KEYWORDS: Camel Wool, LPPS and CC, Camel Breeders \& Sustainable Livelihood
\end{abstract}

Received: May 25, 2020; Accepted: Jun 05, 2020; Published: Jul 10, 2020; Paper Id.: IJTFTAUG20202

\section{INTRODUCTION}

The word sustainable has become quite common throughout the world. Sustainable places people at the core of growth, while rendering development specialist effectiveness to deprived communities are associated with camel wool. The approach of sustainable livelihood is a way of thinking about the priorities, reach, and objectives of development activities. It helps to organize events that are diverse and sustainable in collaboration with the public and the private sectors that are people-centered, sensitive, and participatory, multilevel. I The wool fiber from sheep's different breeds is by far the most widely used animal fiber. The largest group of fibers is derived from related species such as goats and camelids, categorized as hair specialty fibers and graded as "wool" under the American Wool Act. These fibers are classified as hair fibers in the textile processing trade as they require special processing conditions and equipment. Cashmere, mohair, and Camelidae fibers are generally acknowledged having special properties of softness, smoothness, and luster. They also have other characteristics that influence consumer understanding of the market such as rareness, exotic manufacturing locations, and are associated with luxurious, comfortable, and exclusive clothing and other items. Thus camel, goat, and other animal fibers are known as speciality or luxury fiber. ${ }^{\text {II }}$ There are two types of Camels: Dromedary and Bactrian camel. The camels belong to the family of Camelidae with two subfamilies: Camel and Lama. The Camelus group consists of two species: the one-humped camel (Camelus dromedaries) also known as the dromedary and the two-humped camel (Camelus bactrianus) also known as the Bactrian camel. But Dromedary camels are available only in India. Dromedary Camels, which live in hot climatic conditions mostly, do not produce 
long coats. Camel wool has traditionally been used in making of rough cloth, blankets, bags, ropes, etc. It is also used in mats, carpets, blankets, animal covers, and carriage bags. ${ }^{\text {III }}$ Due to lack of awareness and traditional production of fiber processed quality products of a commercial-grade are not usable. LPPS (Lokhit Pashu Palak Sansthan) is a Rajasthan-based NGO that conducts income-generating activities, training on better ways to process, spin, and weave camel wool. Several scholarly works have also been done on the other varieties of camel wool research and they enhance their textile performance. The supply of camel wool is very small, and concerted efforts are needed to help this wonderful fiber emerge from the forest and take its rightful place in the textile world.

LLPS (Lokhit Pashu Palak Sansthan): LLPS means "pastoralist welfare institute" which is situated in village Sadri District Pali, Rajasthan. LPPS grew out of its contribution to the camel pastoralists in the Godwar area and has close ties with the Raika/Rebari community. LPPS's main objective is to support and learn from pastoral communities as proponents of animal husbandry that are ecologically sound and socially just. ${ }^{\text {IV }}$ People of LPPS use camel wool to develop products for self- use to survive for the self economy.

Camel Charishma: CC is a social enterprise aimed at developing, encouraging, and selling environment-friendly camel goods. It was founded by two founders Hanwant Singh Rathore \& Dr. Ilse Kohler-Rollefson in 2010 and was influenced by LPPS experiences and close connection. It was established as a result of LPPS project to revive Rajasthan's camel husbandry to create a sustainable rural livelihood in semi-arid areas, as well as to create opportunities for local communities to earn jobs. Camel Charishma's aim is to provide economic incentives for camel breeders to continue keeping camels for their livelihood and contribute to the Thar Desert's sustainable management and conserve this rich agro-ecosystem of biodiversity. A range of products from camel milk, camel wool, and camel dung have been developed over the past few years. Our goods are all-natural, environmentally friendly, and handmade by local communities in Rajasthan. ${ }^{\mathrm{V}}$ The main source of earning for local people is to develop products of the camel. Widow women spin camel wool for goods, and mostly for rugs at their homes in a village near Jaisalmer. The people of LPPS use camel wool to make some products but only for self- use to survive for their self economy. ${ }^{\text {VI }}$ And especially camel wool used by camel breeders to be used as rugs, mats, saddle girths, and charpais in their own homes. Camel breeders historically were unable to sell camel wool because of some civilizing limits and also low wool short fiber revenue. And the scope for commercial use of camel wool is quite limited.

\section{OBJECTIVES}

This research aims at reflecting light on the fundamental objective and aims as follows:

- To study social and economic aspects of camel wool by camel herders.

- To study the existing products developed by camel breeders.

\section{RESEARCH METHODOLOGY}

The research methodology of this paper is based on Primary and secondary data. Under the primary method of data collection, the research methodology is conducted as a pilot study and the instrument is the observation and personal interview schedules. Such interviews are being performed at LPPS for camel wool items for the survival of Sadri camel breeders. The data is also collected from the secondary sources through various journals, websites, books, newspapers, editorials, published and unpublished research thesis, etc. 


\section{RESULTS AND DISCUSSIONS}

This research is based on observation and interview schedule. The researcher takes an interview with Mr. Hanwant Singh Rathore who is the secretary of LPPS and founder of CC and with his other team members. After taking the interviews, researcher found that the method of purchasing camel wool from breeders / artisans is that Raika shears their camels on 60 Rs per $\mathrm{kg}$ at the time of Holi than CC buys camel wool from the camel herders working for CC as well as LPPS. It is envisioned that all the artisans/breeders get their respective work from LPPS. Every single respondent works for it and they also work for self-purpose. After obtaining the camel wool, color-wise separation is done by hand and this process is called sorting. A minimum number of women artisans are engaged in this process. Some male artisans clean raw wool after sorting and, with the help of a carding machine, separate it into fine and coarse fibers. A wool carding unit is available at CC. The coarser wool is spun by men with the drop spindle, while fine fibers spun into yarn with the Gandhi Charkha by Jaisalmer women. Most of the women are spinners who spin fine camel wool yarn by Gandhi Charkha at their homes. Coarser wool is used for rugs, carpets, mats, and other products woven by weavers with the help of pit loom and handloom at Bhawrani and Barmer. While fine fibers are made into shawls in collaboration with Kullu Karishma. Due to the fundamental knowledge of weaves, artisans use very basic weaves and develop very simple designs. They use only plain weave and tapestry in Durries, and Carpets. Artisan used mainly three kinds of processes to produce different types of products. These are mainly weaving, braiding and spinning. Products like carpets, durries, saddles, mats, stoles, and pouches are developed. These are very basic products which are developed by artisans. According to the collection of data, the artisans get their payments through the respective center. The payment is not fixed but it all depends on the type of work, time, and material. Wages of spinners are 5000 to 6000 per month. Wages of weaver depend on the basis of per meter of the fabric construction and quality of fabric and wages are 150 per meter. Women artisan gets around 200 Rs/day for sorting. They sell their products in Pushkar fair and also at inner-city stores. They also use products in daily life for self-use. LPPS provides the supplementary source of income for breeders/artisans.

\section{CONCLUSIONS}

Observation and interview schedule reveals that camel hair is used by the breeders only to make the basic products for their livelihoods. Presently, their social and economic status is very low. Despite all the excellent qualities, Camel hair is most commonly used for making basic products like rugs, blankets, ropes, charpais, etc. In products, new designs are lacking and existing designs are very basic. They often use only 'camel' as the motif, especially in Durries. There is also a shortage of added value products. One of the reasons for this is that breeders and others have not made efforts to create new goods that would be interested in consumers in the inner city. Design Thought, Design System, and Process is insufficient for creating any product.

\section{SUGGESTIONS}

Production of Camel wool is one of the significant rural employment opportunities. It is a supplementary source of income for the camel breeders. It could contribute to the region's economic development and therefore prevent migration from supporting its traditional regional art and crafts. So there is a need to develop innovative designs and attractive products. By conducting various workshops on weaves, designs, color combinations and innovative products can contribute to the development of social and economic aspects for a sustainable livelihood. New products can create opportunities for rural entrepreneurs and their families. 
Existing Products Which Are Developing By Lpps (Lokhit Pashu Palak Sansthan, Sadri, District-Pali, Rajasthan)

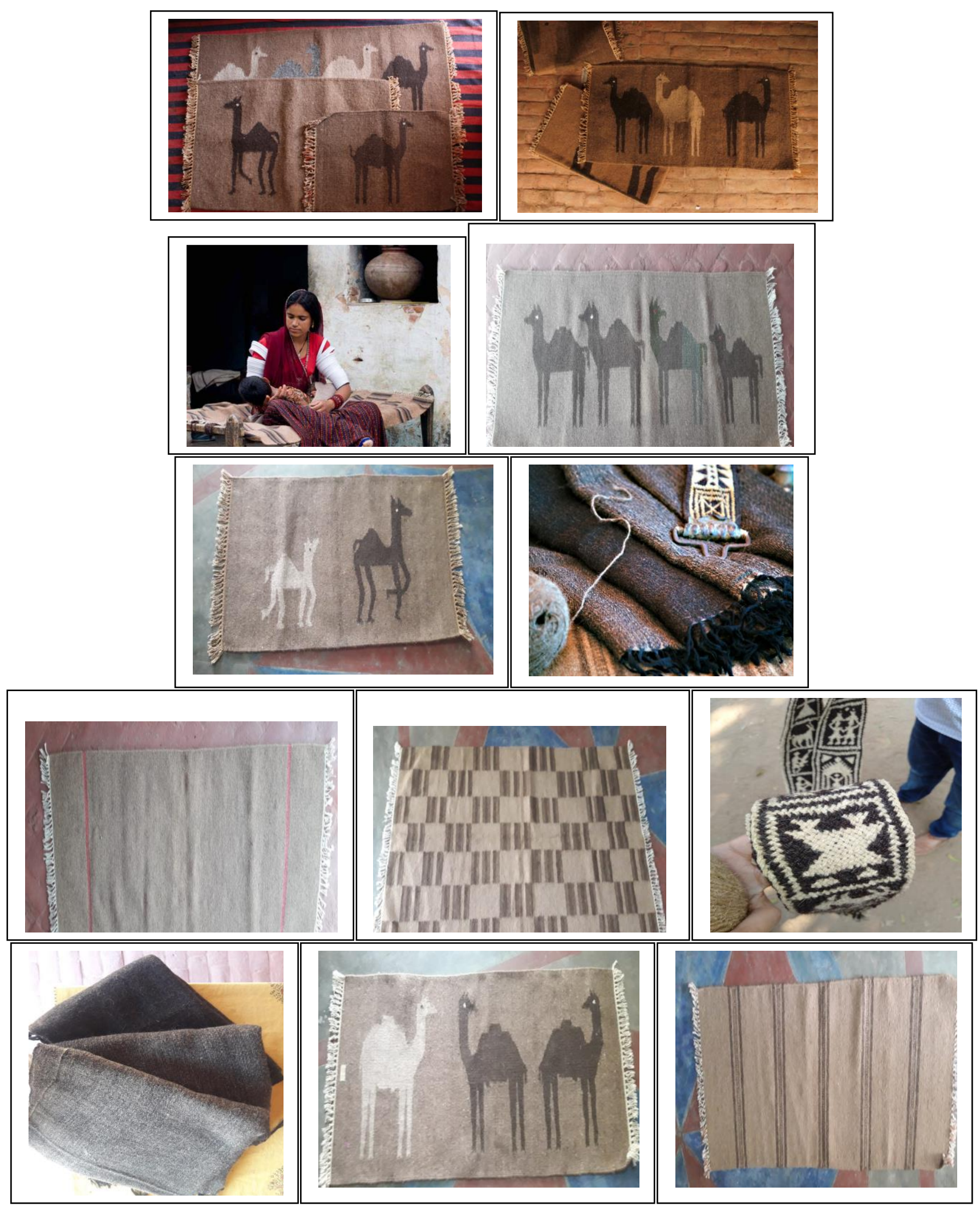

Figure 1 


\section{REFERENCES}

1. Serrat, O. (1970, January 1). The Sustainable Livelihoods Approach. Retrieved from https://link.springer.com/chapter/10.1007/978-981-10-0983-9_5 (Accessed on 20-12-2019)

2. DiSalvo, M. (2018, November 22). Luxury Wool and Eco-Friendly Cashmere Alternatives. Retrieved from https://shopvirtueandvice.com/blogs/news/luxury-wool. (Accessed on 3-03-2019)

3. Khanna, N. D., \& Rai, A. K. (1991). Camel Rearing in the Indian Arid Zone. Annals of Arid Zone, 30(1), 1-10. Retrieved from cazri.res.in/annals/1991/1991M-1.pdf

4. About LPPS. (n.d.). Retrieved from http://www.camelsofrajasthan.com/about-lpps. (Accessed on 7-04-2019)

5. Camel Charisma - Reviving the Camel Wool Weaving and Rug Craft. (n.d.). Retrieved from https://www.camelcharisma.com/paper-wool/wool/. Accessed on 29-12-2019)

6. Lokhit Pashu Plalak Sansthan (February, 2010). Camel value addition: A tool for sustainable rural development in Rajasthan. Retrieved from http://www.lpps.org/wp-content/uploads/2013/09/Camel-Value-Addition-Report.pdf (Accessed on 24-12-2018) 
